\title{
Multimodality, creativity and children's meaning-making: Drawings, writings, imaginings
}

\author{
Zannie Bock \\ Department of Linguistics, University of the Western Cape, South Africa \\ E-mail: zbock@uwc.za
}

\begin{abstract}
This paper uses a case study of the drawings, early writings and imaginative role play of two children to illustrate how children use a variety of modes to make meaning in ways that are creative and beyond the design and expectation of adults. It aims to valorise the kinds of practices in which children routinely engage but which are often overlooked and de-valued by adults, both parents and teachers. Framed by social semiotic theories of communication, multimodal pedagogies and cognitive accounts of children's drawings, it illustrates how the children in this study work easily and seamlessly across a variety of materials and modes, using the semiotic resources available in their environments, to create imaginary worlds and express meanings according to their interests. In profiling these children, this paper lends support to the claim of multimodal pedagogies that it is the shifting across modes, as well as the freedom to choose the mode of expression, that engages the child's affect and creativity and builds agency and voice.
\end{abstract}

Keywords: children, meaning-making, drawings, early writings, multimodal pedagogies

\section{Introduction}

This paper uses a case study of the drawings, early writings and imaginative role play of two children to illustrate how children use a variety of modes to make meaning in ways that are creative and beyond the design and expectation of adults. It aims to valorise the kinds of practices in which children routinely engage but which are often overlooked and de-valued by adults, both parents and teachers; and to support calls for approaches that draw on multimodal principles in early literacy education (see, for example, Early and Kendrick 2015; Stein 2007). Framed by social semiotic theories of communication, multimodal pedagogies and cognitive accounts of children's drawings, it illustrates how the children in this study work easily and seamlessly across a variety of materials and modes, using the semiotic resources available in their environments, to create imaginary worlds and express meanings according to their interests. In profiling these children, this paper lends support to the claim of multimodal pedagogies that it is the shifting across modes, as well as the freedom to choose the mode of expression, that engages children's affect and creativity and affirms their sense of agency and voice. In this paper, I use agency to refer to the development of sign-makers as "designers of 
meaning" who exercise "semiotic choice" and "self reflexivity" (Archer and Newfield 2013:6), and I use voice to refer to the capacity to "make oneself heard', particularly in contexts of inequality (Blommaert 2005).

This paper begins by reviewing different multimodal theories, in particular those of Gunther Kress (1997, 2000, 2010), and contextualising these within a history of semiotics. It then proceeds to the case study of the two children in question.

\section{Theoretical framework}

Theories of language and semiotics have undergone major paradigm shifts over the past century, from Saussure's (1916) theory of the sign and the structuralist approach of the early 1900s, to the beginnings of the social turn in the 1960s (Kress 2001). Yet another significant shift occurred in the 1990s, when scholars began challenging the primacy of language as the object of study and argued for a view of all communication as multimodal. They pointed to the growing importance of this perspective, given that we live in an increasingly mediatised and technology-driven world in which different forms of visual communication play an ever greater role (see also Crafton, Silvers and Brennan 2009; Jewitt 2009; Kress 2010; Kress and Van Leeuwen 1996).

These paradigm shifts have been articulated by a number of overlapping scholarly fields since the 1990s, in particular multimodality (Kress 2010; Kress and Van Leewen 1996), multimodal pedagogies (e.g. Jewitt and Kress 2003), New Literacy Studies (NLS) (e.g. Street 1995) and multiliteracies (e.g. Cope and Kalantzis 2000). Street, Pahl and Rowsell (2009) explore the synergy between these fields and argue that while studies of multimodality bring recognition of the multimodal nature of texts to the ethnographic perspective of NLS, the latter brings an emphasis on practice and context to the more textually-driven focus of the former. What all these approaches have in common is the recognition that a much broader understanding of language and communication is needed to deal with the range of representational practices that is integral to contemporary life.

From a pedagogic point of view, a multimodal approach to learning "treats all modes as equally significant for meaning and communication" (Kress and Jewitt 2003:2) and recognises that all modes, not just language, enable cognition and development. In contrast to traditional Western practices of schooling that privilege prescriptive notions of writing over drawing and language over music and art, multimodal approaches "open up full and productive access to the multiplicity of representational and communicational potentials" (Kress 2000:159). These are viewed as essential for learning and participation in the new technologically-driven economies of the $21^{\text {st }}$ century.

The analysis of children's drawings and multimodal play in this paper is framed by insights from these fields, in particular the work of Gunther Kress and colleagues (e.g. Kress 1997, 2001, 2010; Jewitt and Kress 2003; Newfield 2009, 2013; Stein 2003, 2007). In the rest of this section, I provide an overview of Kress's theories - both on the nature of communication and on the ways in which children engage with and are schooled into different semiotic worlds before turning to scholarship that explores the multimodal pedagogies his ideas have inspired. The theoretical framework for this paper also draws on the work of Maureen Cox $(1993,2005)$, a psychologist who has studied the development of children's drawings for the past three 
decades. Whilst Kress's work is socio-cultural in orientation, Cox's is primarily cognitive in the Piagetian tradition. Their perspectives are complementary in that they each foreground different aspects of children's creative expression. Kress (1997:166) himself acknowledges his intellectual debt to Cox in his seminal book on children's multimodal expression, Before writing: Rethinking the paths to literacy.

\subsection{A social semiotic, multimodal approach to communication}

Drawing on his experience in language and literacy education, and with acknowledgements to his many collaborators, Kress (2010) proposes a social semiotic, multimodal approach to contemporary communication. In this theory he takes issue with Saussure's fundamental tenet that language is a system of arbitrary signs governed by rules which serve to 'fix' the inherent variability of language and keep it stable. Instead, he argues that language is inherently fluid and dynamic because the relationship between the material form of the sign (the signifier) and its meaning (the signified) is not arbitrary but motivated by the sign-maker's interest. He elaborates this as follows: people "use the resources that are available to them in the specific socio-cultural environments in which they act to create signs" (Kress and Jewitt 2003:10), and as there is never a total 'fit' between the sign and the intended meaning, the signs are minutely made and remade with every new use. Thus the meanings of signs are constantly transformed as sign-makers select the most apt sign from the available resources in any given context according to their interest.

Kress argues further that language is no longer the most important or even the most powerful means of communication, and that the meaning of any message is distributed across a range of modes. Kress and Jewitt (2003:1) define a mode as a "regularised organised set of resources for meaning-making, including, image, gaze, gesture, movement, music, speech and sound-effect". Any material, whether drawn from nature (e.g. feathers, wood, metal) or cultural history (e.g. words, music, dance, 3D objects), may act as a mode. Over time and with repeated use, these modes begin to reflect 'regularities' and conventions, or 'grammars'. They then become understood and are therefore usable by members of a culture for representation and communication. The more these modes are used in the social and cultural work of a community, the "more fully and finely articulated" they become (Kress and Jewitt 2003:2). For example, writing emerged from drawing when images in various parts of the world became organised into systems of representation (e.g. Chinese character-based writing or Egyptian hieroglyphics). Thus modes are understood "to be the effect of the work of culture in shaping material into resources for representation" (Kress and Jewitt 2003:1).

A further concept central to Kress's theory is that of design, as this accounts for how the meaning-maker integrates the different signs and modes in any given message or text: "Design is thus both about the best, the most apt representation of my interest; and about the best means of deploying available resources in a complex ensemble", argues Kress (2000:158). Thus design shifts the frame from the view of language as a bounded system of signs held in place by convention to one in which interest is seen as the "motivating force of representation" (Kress 2000:157).

Children, argues Kress (1997), use a multiplicity of modes and materials to make meaning, and seem to experience no difficulty in moving easily between and across modes (e.g. watch a film about dinosaurs, draw a picture of one, cut it out and use it as a prop in role-playing). The 
culture into which they are born provides the "stuff which is to hand" (Kress 1997:94), but how they semiotically recycle this in creative and transformative ways is guided by what captures their interest at that moment. However, these semiotic expressions may only relate indirectly, if at all, to adult expectations of what constitutes appropriate sign-making; and may therefore remain unacknowledged and undetected. As a result, children's efforts to externalize their ideas and thoughts may not be valorized. The ability to create signs and act upon their culture is, argues Kress, an essential part of the child's development of a sense of agency and voice.

\subsection{Multimodal pedagogies}

A number of scholars have explored the implication of this approach to literacy and learning (e.g. Jewitt and Kress 2003; Newfield 2009; Pahl 2003; Stein 2003, 2007; Stein and Slonimsky 2006). Central to these pedagogies is the recognition that modes have different meaning potentials (affordances), and that the reworking of meaning across different modes is a powerful stimulus to learning. This transformation is variously referred to in the literature as recontextualisation (Pahl 2003; Stein 2003), synaesthesia (Kress 1997), transmodalisation (Newfield 2009) and transmediation (Crafton et al. 2009).

A compelling example of this approach in action is Pippa Stein's (2003) study of children's meaning-making in the Olifantsvlei 'Fresh Stories' project in a school in an informal settlement on the outskirts of Johannesburg. Here she focuses on how 3D doll figures produced by children become resources for them to express and embody ideas and characters with which they can identify. She argues further that in taking ownership of the dolls' production (as the children did) by choosing to make them at home with materials found in these environments, they were able to draw on traditional cultural practices around fertility doll/child figures, thus enabling their mothers and community members to become sources of knowledge in their making. The dolls formed part of a larger project, which included 2D drawings, writing, spoken dialogues and multimodal performance; and Stein argues that it was the conscious and systematic shifts across modes that were the really significant factor in learning.

Drawing on Hofstadter's (1985) theory of creativity, Stein argues that these resemiotisations are the key to 'unleashing' children's creativity, reshaping their knowledge and stimulating learning. She bases this on Hofstadter's (1985:233 cited in Stein 2003:134) claim that "(m)aking variations on a theme is really the crux of creativity": as the concept or idea passes from one mode to the next, it develops in ways that are unexpected and unanticipated, thereby enabling multiple variations (of forms, shapes, colours, patterns, words and images) to emerge. Further, as concepts 'migrate' across modes, they 'slip' into one another with unpredictable results. Thus "although the object appears to be 'fixed' in the sense that it materialises into what appears to be a static text, the meanings attached to the text are unstable and fluid within the semiotic chain", argues Stein (2003:136). What the children finally chose to use as representational resources depended not only on what was available in their environments, but also on their interest - an outcome of their agency as makers of meaning. She therefore argues that learning should where possible take place within an 'unpoliced zone' so as to allow children unrestricted choice in terms of the 'stuff' of their representation (2003:124).

These insights are supported by Kate Pahl's (2003) case study from a very different context: a middle-class London home. Here she shows how one boy over a period of two years (aged 68) drew on popular culture (Pokémon characters) and a range of multimodal resources (drawing, 
3D modelling, photography, writing, speaking) to create a fantasy world in which he takes on different identities (professor, inventor). Like Stein, she draws attention to the fact that it was the materiality of the forms that was of primary interest to the boy (he liked 3D forms, not "flat stuff" (2003:152)), and also argues that it is the recontextualisation across modes and the different affordances that these offer that opens up the creative space within which he can experiment and innovate. She concludes that a study of these shifts allows the child's "unique learning paths" to be recognised and understood, and that these insights should be extended to the school context so that "the child could be supported in a multimodal learning environment to invent meaning" according to his interest and intention (Pahl 2003:154).

Denise Newfield $(2009,2013)$ explores what she refers to as 'transmodal moments' in a range of South African classrooms spanning contexts of socio-economic advantage and disadvantage. She defines these as "the moment of shift in a transductive process of meaning making" (2009: 84 ), or those critical moments in the meaning-making process when the sign-maker shifts mode based on his or her interest and in accordance with his or her sense of aptness or design. Newfield's study shows how, for her participants, these moments can lead to changes in subjectivity (how the sign-makers view the world), and trigger "moments of learning" (2009: 184) in which the heightened enjoyment enabled by this approach plays a powerful motivating role.

Thus, in a social semiotic, multimodal approach to learning, creativity is valued and signmaking is recognised as a complex process of design in which individuals are seen not as users of a stable system but as remakers and transformers of "sets of representational resources ... in a situation where a multiplicity of representational modes are brought into textual compositions" (Kress 2000:160). Different modes are recognised as having differential potentials for learning and the shaping of learner identities, and learners are encouraged to make meaning in innovative ways which engage their affect and interest. These scholars argue that creating spaces for this kind of exploration both within and beyond the classroom stimulates imagination, experimentation and learning. Even more significantly, it develops the child's sense of agency and voice.

\subsection{Developmental sequences in the representation of human figures}

While Kress and the above scholars describe their approach as rooted in "social accounts of cognitive action", where the emphasis is on "socially formed and socially located individuals and their active remaking of their environment" (Kress 1997:167), Maureen Cox $(1993,2005)$ follows in the cognitive tradition of Piagetian psychology. Cox's focus on the developmental ability of young children in Western societies to draw the human figure offers us a means to analyze the recontextualisation of children's representations over time. In this way, her work complements Kress et al.'s focus on transformations across modes by bringing in a developmental and temporal perspective.

Cox (1993) credits Luquet $(1913,1927)$ as her inspiration, and notes that his work also influenced Piaget (1954) and his theory of childhood development. However, she argues that children's increasing ability to draw should not be conceived of in the Piagetian sense of discrete, consecutive stages which must be passed through in a particular order with each new stage replacing the previous. Rather, she argues that as children's fine motor control and cognitive skills develop they are able to add to their repertoire of representational forms and 
strategies, but forms from an earlier stage may co-exist with those from a later one. Cox argues further that variation in a child's representational forms may also be affected by more mundane factors within the situational context: the children may simply be bored, or influenced by a teacher's instructions or the way that other children around them draw. She quotes Paget (1932 cited in Cox 1993:116) as saying that "the primary influence on children's drawings is not so much the adults' mode of representation but the way that other children draw". The schema for drawing a figure or body part is observed, absorbed, repeated and passed on to succeeding generations of children in the same way that children learn games from each other. Thus Cox (2005:178) recognises that children's abilities are not only affected by their level of motor control and cognitive development, but also by their intention (akin to Kress's notion of interest) and their socio-cultural context.

\section{Context and data}

Children's drawings have been the subject of interest and study for more than a century. Researchers who have published in this field, often drawing on the work of their own children, include none other than Charles Darwin, who published a study of his son's drawings in 1877 (Cox 2005). Two of the scholars whose theories have strongly informed this paper, Gunter Kress and Maureen Cox, also studied their own children. This paper follows in that tradition by analysing my own children's expressions of meaning through drawings, early writings and imaginative multimodal play.

The children in question are brother and sister. At the time of this study, Mikki was 11 and a half years old and in Grade 5. Andrea was 8 and in Grade 2. They had both attended a German kindergarten and, at the time of this study, were enrolled at a German-medium school. They spoke German with their father, although English was the dominant home language. They were raised in a middle-class, print-rich environment, and their exposure to different forms of literacy reflects their privileged background. However, the kinds of practices they engaged in, as reported in this paper, are not necessarily dependent on this advantage. As Stein (2003) has shown, the kind of creative play with recontexualised objects that Mikki engages in (as detailed in this paper) relies on imagination and innovation, which children from all backgrounds have in abundance.

This paper, then, explores the different ways in which these two children utilise a range of semiotic resources to make meaning. As with many siblings, the two children are very different in their interests and habits, and their modes of expression over the years have been similarly diverse. Andrea likes to draw and write; her brother was never very interested in 'wielding the pencil', preferring to give expression to his fantasies through free and imaginative play using discarded objects as props. I analyse each child's meaning-making separately, before reflecting on the implications of the analysis for learning and literacy development.

\subsection{Andrea's drawings}

Andrea's drawings and early writings span a period of 4 and a half years (between the ages of 2 years 10 months and 7 years); in other words, from the time she began creating pictures with some recognisable representational content to the middle of her first year of school. The data set consists of over 250 drawings and literacy artifacts (cards, booklets, letters, envelopes, and so on) which I collected, dated and filed over the years. These drawings are overwhelmingly of 
people, in particular decorated female forms (fairies, princesses, 'mommies' with babies, 'mommies' and daughters) and houses or detailed interior rooms. As an 'artist', Andrea was confident about her ability, drawing quickly and effortlessly, and describing herself as "the best drawer in the class".

Cox $(1993,2005)$ traces the developmental sequence that children in 'Western' cultures typically go through as they learn to draw. She describes this as beginning with scribbling at about one year of age, which, she argues, may be the outcome of a child's experimentation with making marks on the page, or representational in the sense that they may represent the movement of, say, a car. According to Cox, the first recognisable human form in Western children's drawings is usually the 'tadpole', a figure with a huge head (often with some facial features such as 'eyes') and legs. The emergence of this form may begin as early as in the child's second year of life, but generally appears when the child is about three or four years old. This way of drawing, argues Cox, is probably due to the fact that the child has not yet devised a 'schema' for the torso. Furthermore, they are usually restricted by their limited repertoire at this point to single lines, roughly circular shapes and dots. In her experience, tadpole-drawers are able to identify their own 'bodies' and 'tummies', but have not yet developed the representational means to draw them (1993:25).

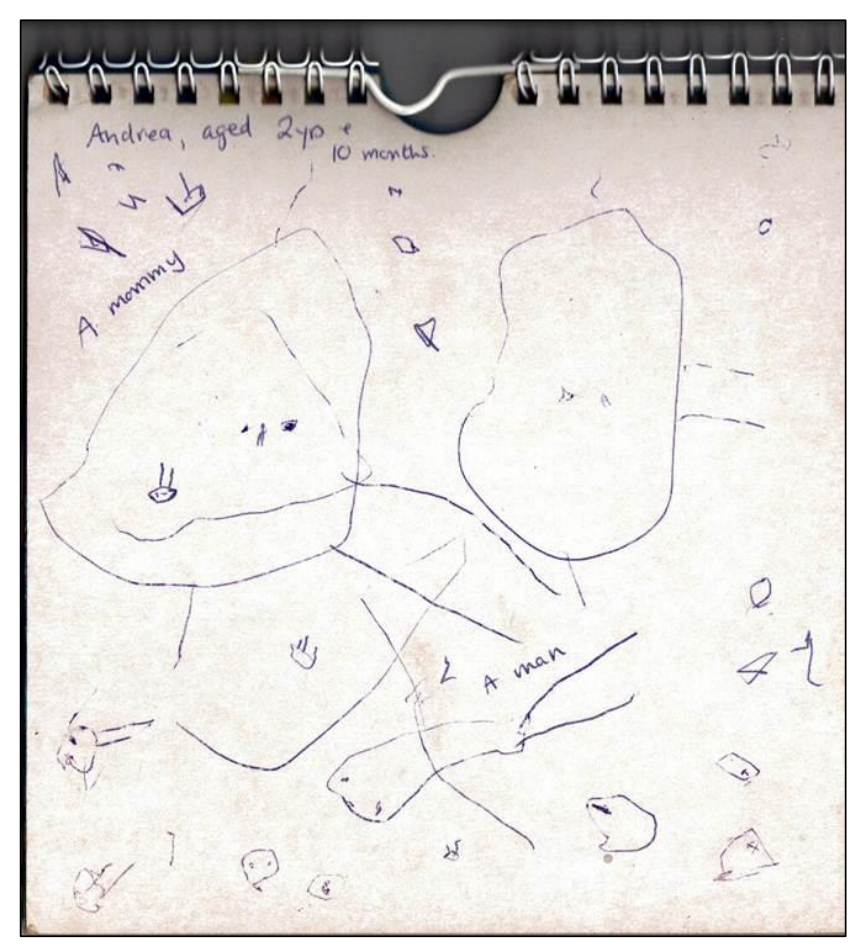

Figure 1: "A mommy and a man"

Figures 1 and 2 represent two such tadpole drawings from Andrea's collection. Figure 1 is the first record I have of Andrea's tadpole drawings, and is dated 2 years and 10 months. It contains a large 'mommy' figure, 'a man' and several other tadpoles and squiggles. (The annotations were added at the time, when I asked her what she had drawn.) Cox argues that children may well begin with the figure that is most important to them, and therefore the larger size may be an indication of the importance of that person. In Kress's (1997) terms, the motivating impulse for the choice of signified (the larger form) reflects what the child finds most salient and 
therefore of primary interest (the importance of the mother). However, Cox also warns against reading too much into the fact that the mother figure is so big, arguing that this may also be the outcome of a planning problem: children frequently draw the first figure as the biggest and most detailed, and then run out of space and energy when it comes to the additional ones.

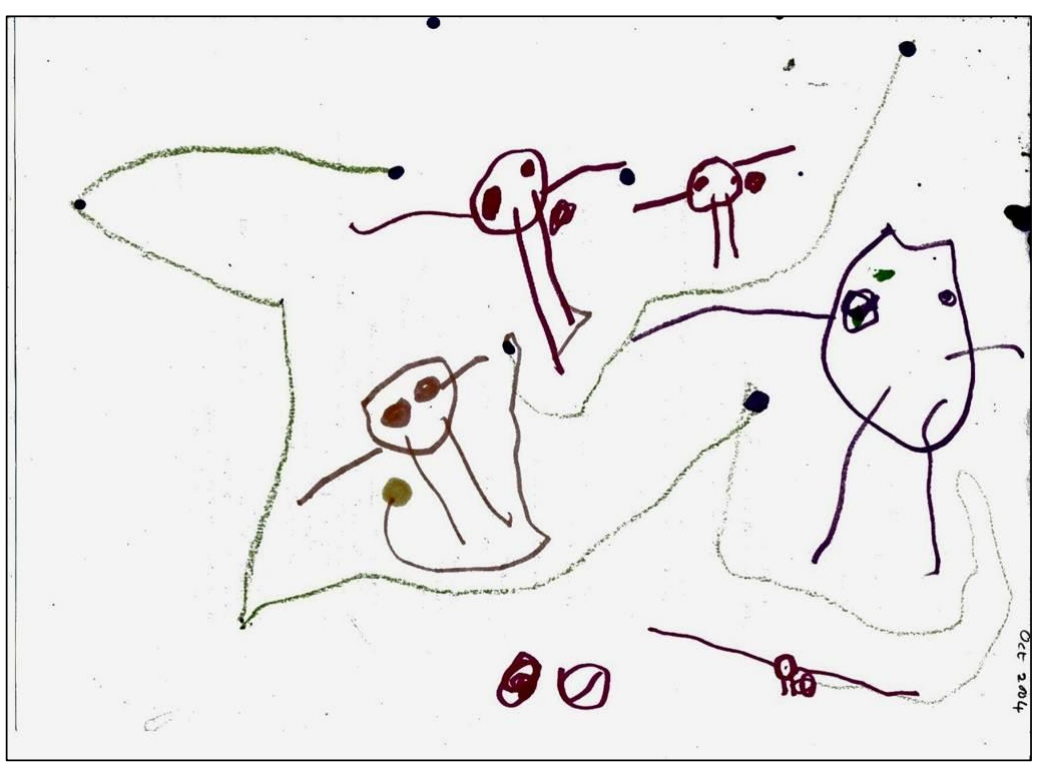

Figure 2: A family group

Figure 2 is dated 3 years and 3 months. It contains five tadpole figures in different colours and a series of dots and lines joined together. When I asked Andrea what she saw in this picture, she said 'a family with a cat'. It could well have been intended as a family portrait: the figures seem to be 'arranged' in a group and the relative sizes suggest two adults, two children and an animal. The amount of effort that went into the selection of colours (five koki colours, one crayon colour), as well as the way in which the dots are carefully joined by lines, suggests a concern with the aesthetic beyond the experiential or representational content of the picture. From a socio-cultural perspective, the effort she expended here can be seen as motivated by her interest on this occasion and as evidence of the importance of design in the composition.

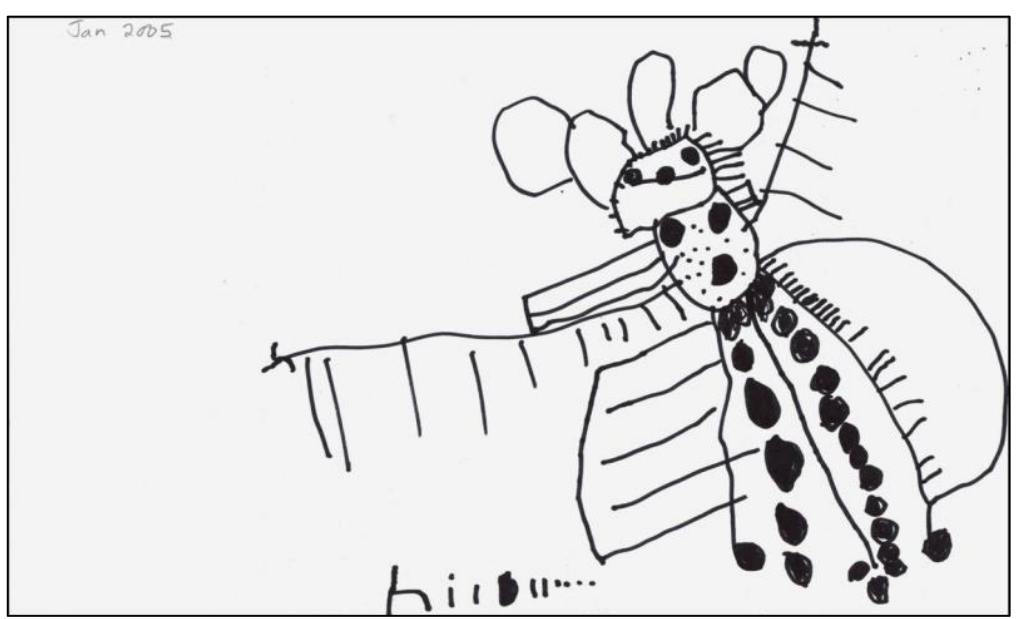

Figure 3: "Girl with a big skirt" 
Figure 3 is the first record I have of what Cox would call a 'conventional figure', or a figure with a head, torso, arms and legs. According to the notes I wrote on the picture at the time, this was done when Andrea was 3 years and 6 months old, and is a picture of 'a girl with a big skirt'. It also includes her first attempt at her name. The name is a series of lines and dots, but with an unmistakable 'i'. Andrea liked the letter 'i' from an early age, probably because it was an important letter in her brother's name (which he was writing on all his artworks at the time), as well as being within her repertoire of lines and dots. From a literacy point of view, she has already worked out that writing happens in a block, usually at the bottom (or top) of the page, and from left to right. As Lillis (2013) points out, writing is a multimodal (not only verbal) phenomenon, and experimentation with the visual (colour, size, font, orthography) and spatial (layout) dimensions of writing is an important part of acquiring literacy.

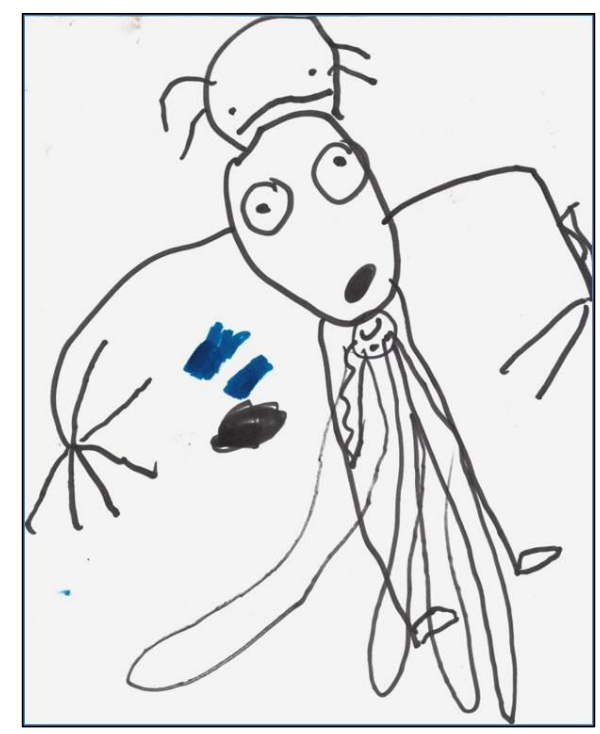

Figure 4: Mother giving birth

Figures 4 and 5 are interesting because they reflect the way Andrea drew before she became too influenced by the styles and conventions of drawing at her kindergarten. Figure 4 is an unusual picture of a 'mommy giving birth'. This was drawn when she was 3 years and 9 months of age and had been at kindergarten for only 3 months. The subject matter reflects her fascination at the time with mothers, babies, births and breastfeeding. The salience of the birth process is represented by the lines of flow emanating from the baby's head as it emerges from the mother. Her interest in breasts and belly buttons is signaled by their prominent forms (note the less obvious head above the torso). In Kress's terms, these are all 'motivated signs' and are indicative of her interest and affect. This drawing is additionally unusual because, according to Cox, genitalia are seldom represented in Western children's drawing due to the taboos associated with them; but here, at the start of her schooling experience, she has not yet been inducted into this social convention. However, this is the last time she draws women with breasts.

At this point, her drawing takes off and she begins to produce numerous drawings. In these the figures become much more stylized, as they reflect the influence of the school and her emerging schema for drawing people. The figures in Figure 5, with their wings and feeler-like arms and legs, are typical of a style she adopted in the middle of her first year of kindergarten (at around 
four years of age). They are probably the result of peer influence as, according to her teacher at the time, a number of the girls in the class were drawing figures like these.

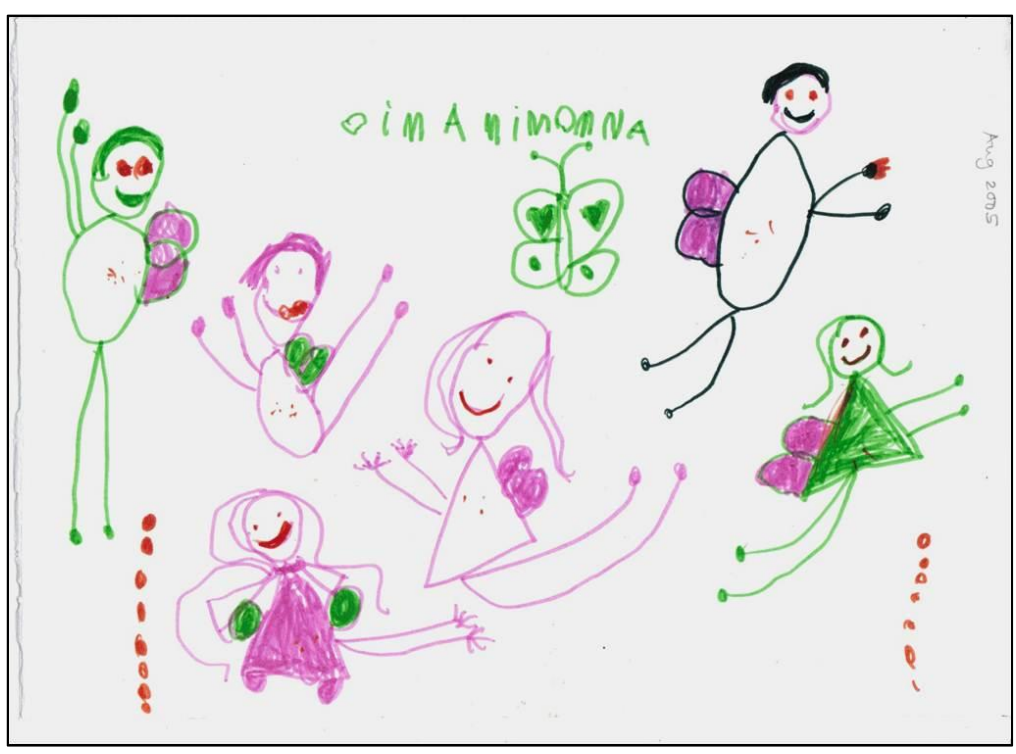

Figure 5: Beetle people

Many of these early forms (ages four to six) are very stylized or, in Cox's (1993:44) words, "rigidly schematic drawings", as the child develops an internal schema which becomes wellpracticed and automatic; a "short hand" (1993:31) for representing objects and people. As noted earlier, these schemas are often 'passed around' between networks of children, giving rise to quite 'formulaic' representations. Cox adds further that some children seem very reluctant to change these stylized forms, while others are prepared to experiment, modify and add more detail. Sometimes they will combine a range of styles in one drawing (e.g. tadpole and conventional figures). Cox indicates that the reasons for this are not clear, but could reflect the fact that children may, when drawing, selectively focus on elements that they consider most salient and interesting (e.g. significant foregrounded figures may be drawn conventionally, while tadpole figures may be used for less important people). Alternatively, the variation may simply be the result of the child forgetting to include a particular body part or of having lost interest in expending the extra effort needed to produce a more detailed form.

Figure 5 also includes some early writing, which reflects her growing awareness of writing as blocks of forms typically situated at the top (or bottom) of an image. At this point in her development, her writing includes the capital ' $A$ ', ' $M$ ' and ' $O$ ' and the small ' $i$ '. Three of these letters are significant in the names of her family members, MIKKI, MAMA, and, of course, ANDREA; words which she would have encountered at home, often in capital letters. (The ' $\mathrm{O}$ ' is probably simply a form she already has within her repertoire.) The way that she groups the letters and arranges them on the page suggests that she is aware that they represent a particular mode of semiosis (writing as evenly spaced, individual forms arranged in a block). However, the way that they are formed, both in terms of colour and design, suggests that for her their integration into a page's design is also important. Once again, Kress's concept of design is significant: for Andrea, writing and drawing are two modes used flexibly and interchangeably as elements of a single 'whole' page design. 


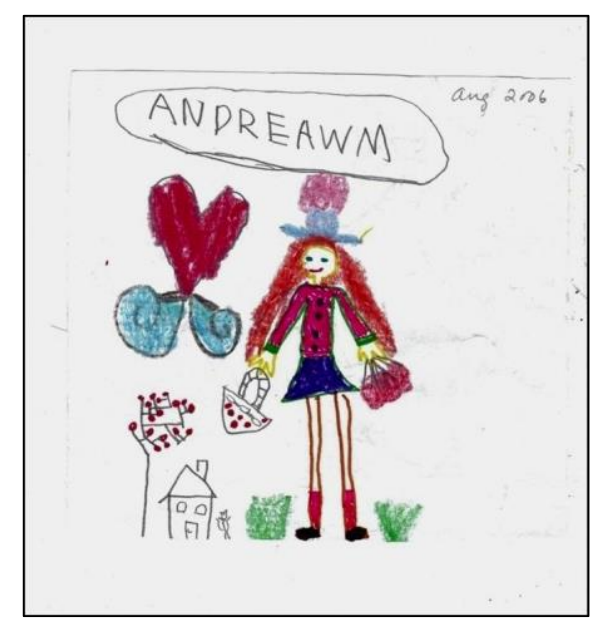

Figure 6: Self-portrait

In Figure 6, drawn a year later when Andrea was five years old, the female figure has developed considerably. The figure is conventionally drawn, with 'contoured' body parts (i.e. arms and upper torso given a single outline to form one unit, as compared to the earlier 'segmented' style, where each body part is represented by a different segment or unit) and presented in considerable detail (clothes, boots, hair, hat, baskets, and in the background a house with a fruit tree and a large butterfly). The orientation is known as 'canonical' (i.e. frontal view); and the body parts do not overlap, which is typical for this age.

Her writing has also developed, and she now writes a recognisable name in capital letters in the position of 'heading' on her page. The ' $\mathrm{W}$ ' letter has now made an appearance - it is the first letter in her surname - and the ' $\mathrm{M}$ ' (for 'Mikki' and 'Mama') persists. The letters are conventionally formed with the exception of the ' $E$ ', which has four (as opposed to three) bars. Kress (1997) has written at length about his daughter's experimentation with her name, Emily. In particular, he discusses the fact that her 'E's were typically written with more than three bars. He uses this analysis to develop his argument that the different forms of her name are not the result of (inaccurate) copying, but rather transformative action, the result of her ongoing analysis of and experimentation with word forms, sequence and directionality. He also wonders whether the multiple bars are not an encoding of affect, the result of the great energy and enthusiasm which she brings to the writing of her name.

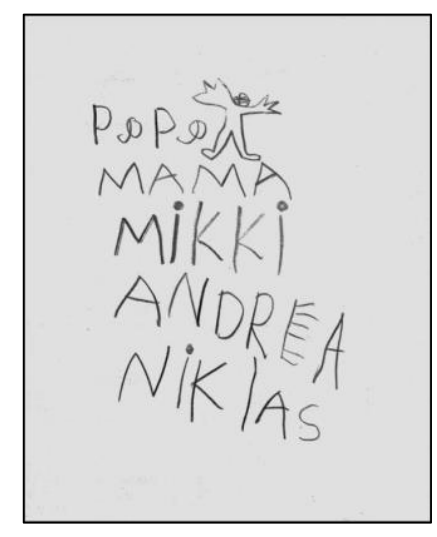

Figure 7: Family names 
Figure 7, produced when Andrea was 5 years and 11 months of age, is a list of the names of the members of her family. However, it is more than a list: it has the design and 'wholeness' that characterises her earlier writings and drawings. In her spelling of 'Papa', she uses an alternative form of the ' $a$ ' which differs from the capital ' $A$ ' she had used up until that point. Her ' $E$ ' has six bars, and the ' $\mathrm{i}$ ' in 'Mikki' and 'Niklas' is still her first and preferred small ' $i$ ' form. The list includes a contoured figure with huge hands, which could represent the Papa or could simply be decorative. Once again, in these early writings, issues of affect and design seem to be important: her first words are the names of her family members, with whom she has a strong emotional connection; and these have been integrated into a design which suggests a real, if unconscious, concern with the aesthetic wholeness of the page. The small image of a human with huge hands has been carefully placed to fill up the 'papa' line and create a 'block' design for the whole image. As argued by Lillis (2013), writing has a strongly visual dimension, which is obscured by traditional schooled approaches to writing as almost exclusively verbal.

Figure 8 is a letter and envelope addressed to a friend of Andrea's mother named Loes, who had written Andrea a letter at an earlier stage. At this point, Andrea is 6 years and 10 months old and has been in Grade 1 for 4 months, where she has been acquiring literacy through the medium of German. However, because she lives in an English-dominant home and a literacyrich environment, she has acquired some English literacy along the way. As a result, her English spelling is largely phonetic.

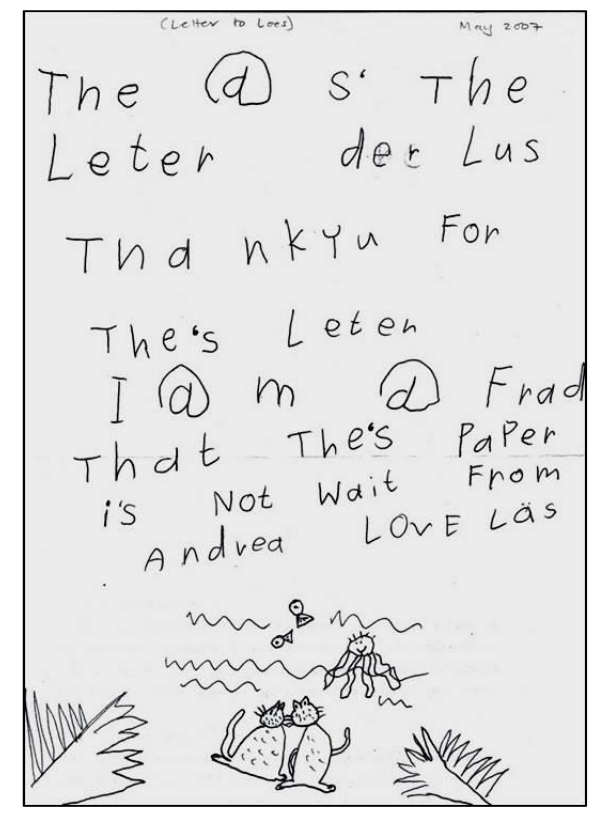

Figure 8: Letter to Loes

At this point, her writing has developed to include an awareness of capitals letters, sentences and the letter genre. Now her experimentation has extended to include the @ sign as an alternative form for the 'a'; as well as the apostrophe, the function of which she does not understand but which she knows appears with an 's' at the end of a word. Her understanding of the letter genre is reflected in the opening address, "There's the letter, dear Lus"; in her stating the purpose of the letter (to thank Loes for her letter); and in the salutation, "From Andrea Love Läs". The "Love Läs" reflects her awareness of the convention that you sign off a letter with 
'Love X', but she is confused as to who should be sending the 'love': it is likely she intends the following meaning: "I send love to you, Loes". The message "I am afraid that the paper is not white" is a comment on the fact that the letter and drawing are done on the blank side of a used piece of paper, and the printing on the opposite side is faintly visible through the page. The envelope (Figure 9 below) also shows her awareness that it should include the name of the person to whom the letter is to be sent, but she has not yet incorporated the concept of an address.

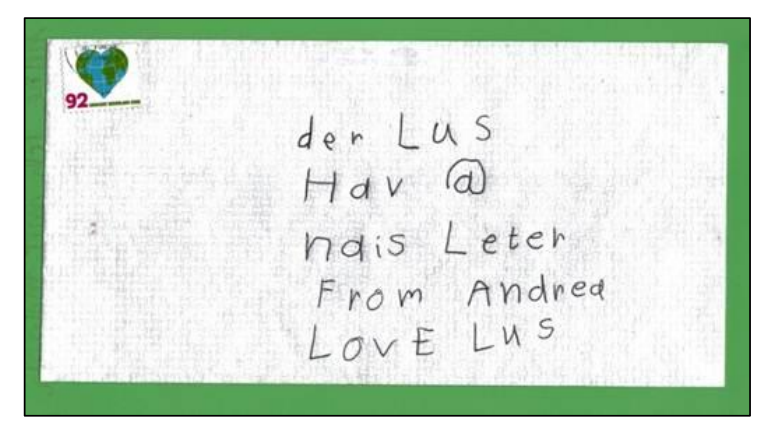

Figure 9: Envelope to Loes

This letter also depicts Andrea's experimentation with the letter ' $a$ '. It includes the small letter 'a', the capital 'A', an alternative small letter form, '@', and the Germanic vowel, 'ä'. While she is clearly experimenting with spelling (e.g. of Loes's name), I would argue that it is also the aesthetic potential of the letter that has caught her attention. The letters are not simply symbols to represent sounds, but forms to be decorated and embellished in different ways. It is the same appreciation of the decorative nature of the letter which, I would suggest, stimulated her early engagement with the dotted 'i' and the multi-barred ' $E$ '. Kress (1997:97) makes a similar argument when he asserts:

For children, alphabetic writing is clearly multimodal: it is blocks of print; letter shapes; media - such as newspapers, birthday cards, books; genres; it is an aesthetic object which can be used in design; a medium of meaning; a drawing of sound; and so on.

The final example of Andrea's drawings, Figure 10, represents the first written narrative in the collection. It shows a picture of three birds, one sitting on a nest while two more sing on the branch of the tree. She first wrote the narrative in German, and then (very accurately) translated it into English on the same day at my request (see Figure 11).

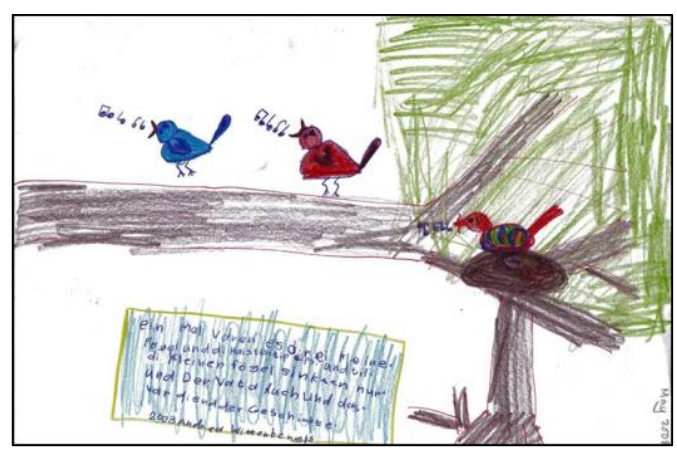

Figure 10: Three small birds 
Once again, this narrative shows her developing awareness of literacy and generic forms. From a literacy point of view, she is still writing in two languages, experimenting with spellings (Vata and 'Vather' for Vater and 'Father', respectively), capital letters and sentence boundaries. In the English version (see Figure 11 below), she seems to be using the German convention that all nouns, which she perhaps interprets as significant words, should be written with capital letters. In the German text, she places a full stop at the end of each line; in the English text, the first sentence is correctly separated from the second with a full stop. In terms of her awareness of genre, she uses the formulaic narrative openings (ein mal varen es, or "Wans There Was") to signal that she is about to tell a story. Her story begins with an orientation, which introduces the main characters and what they were doing. However, at that point, her story ends with the formulaic closing ("and that was the end of the story"). Her narrative lacks a complicating action or resolution in the Labovian sense, and is therefore more of a description than a narrative (Labov 1972). However, it shows her developing awareness of different genres and their appropriate registers.

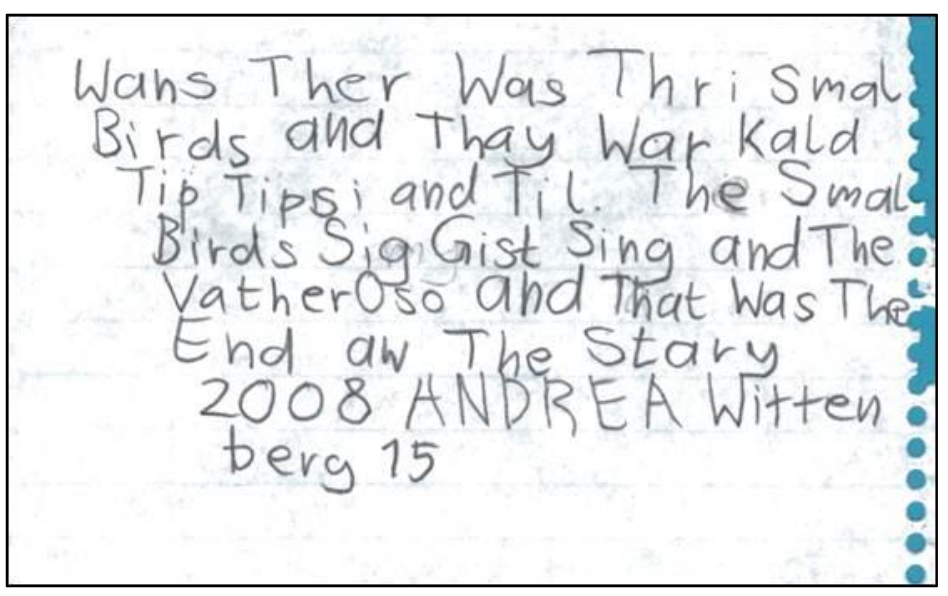

Figure 11: Translation

From a design point of view, the two semiotic modes work together to form a coherent whole. The writing is blocked with a frame and coloured background and bounded by the branches of the tree. The vectors created by the branches lead to the nest on which the father bird sits with a worm in his beak. The fact that it is a father bird (not a mother) is somewhat unusual, but may reflect her experience of her own father, who is the parent who sings with her. She has incorporated the musical notes into her design to represent the singing; further evidence of her developing awareness of different semiotic systems. The orientation of the birds is perhaps unusual in that the direction moves from right to left. However, this may be because she is still not fully socialised into the left-to-right convention of Western page design.

An additional point of interest with respect to this drawing is the way in which the picture evolved: she first drew the picture, then wrote the story. This is a practice I observed on other occasions as well: first she would draw - perhaps an odd collection of animals and people, each one triggered by some random association or prompt from the external environment, without a 'grand plan' - and then write a short story about the picture after the fact. In other words, her drawings acted as the stimulus for writing. In Newfield's (2009) terms, this represents a 'transmodal moment' - a moment in which her sense of design and interest guides her choice 
of mode, and results in a transformation of meaning and a stimulus for learning and literacy development.

According to Kress, children's appreciation of the multimodal nature of communication extends to writing as well. So, when a child takes a piece of paper and folds it to make a birthday card or a newspaper, he or she is experimenting with the media to hand and creatively transforming these for his or her purpose. Andrea's early literacy efforts produced a number of examples of this nature as well (see Figure 12). She loved folding and stapling paper to make booklets and cards and affixing little pieces of coloured paper, stickers and bits of string and ribbon to her creations. As Kress argues, with each new artifact (card, notebook, diary), she experiments with a different literacy genre. She also learns how to manipulate its materiality and transform, for example, an A4 sheet of paper into something new and aesthetically appealing. As Stein and Pahl's case studies show, the materiality of the form is often a highly significant aspect of design for children.

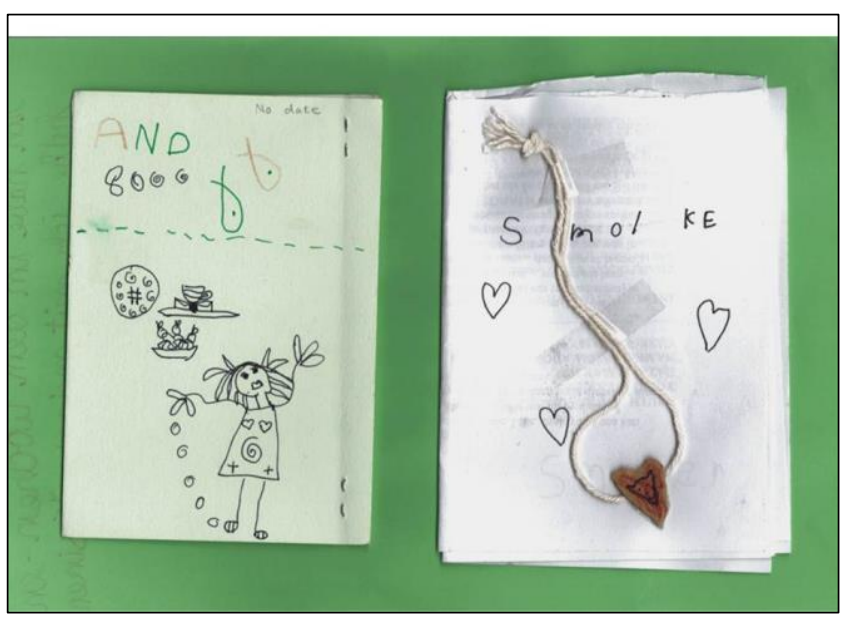

Figure 12: Booklets

So far this paper has focused on drawing, writing and literacy artifacts, all of which rely predominantly on paper and pens. However, as noted above, multimodal pedagogies recognise that children use a variety of modes and materials - whatever is 'to hand' - to make meaning, depending on what captures their interest on that occasion. A different kind of 'multimodal play' is illustrated by the following account of the second child in this case study.

\subsection{Mikki's multimodal play}

In contrast to Andrea, Mikki's file of drawings contains only about 50, and they are mostly of battle scenes; often with elaborately drawn fortresses under siege from dragons or armies of men wielding guns or bows and arrows. They tend to be very stylized, and his depiction of figures has not changed much since he was six years old. As noted above, he did not enjoy drawing or tasks that required this kind of fine motor co-ordination, preferring to express his fantasies through multimodal play. 


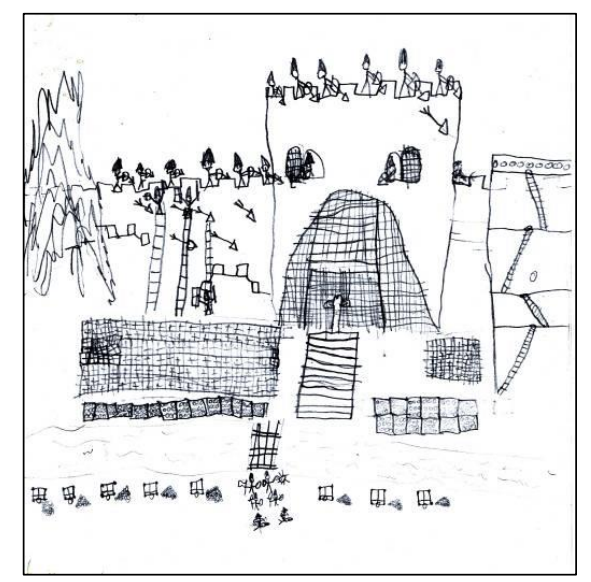

Figure 13: The siege

As an example of this, this section explores a very elaborate war game he developed over several years. This game was located in a few sites in and around the house (as castles and barracks) and included, according to Mikki, more than 1,000 corks which his parents had collected over the years and stored in the garage.

When Mikki was about 10 years old, I became aware of his rather furtive activities in a corner of our garden, where he had constructed what looked to me like a pile of old roof sheeting and bricks, but was according to him a 'castle'. I was also aware that for some months he had been collecting corks in a rather obsessive way. Seeing that he knew I would complain about the fact that his room was already full enough of 'junk' without adding bags of old corks to the mess, his manner was somewhat secretive and evasive, and he did not elaborate on what he was doing. It was only when he came to me in a state of high excitement at the beginning of winter and told me that "a huge evacuation was about to begin" that I realized that something more significant was taking place. The Cork Empire (for that is what it was) was to be moved into its winter barracks inside the house, into a small geyser 'room' in the bathroom which Mikki had appropriated as his 'territory' some time before. Once the evacuation was complete, I asked him to show me what he was doing, and discovered that what I had thought was a pile of roof sheeting and hundreds of corks was in fact a complex Empire, complete with kings, princes, heroes, priests, servants and a highly differentiated army of generals, commanders and legions of soldiers; some human, some mythological. In fact, it was not only corks that were 'resemiotised' as 'men', but old batteries, acorns (some with defining marks cut into them), seeds and cones (see Figure 14). The Empire included practices such as the building of castles, walls and monuments, complete with human sacrifices (represented by cut-up corks). The Empire extended throughout the house and garden. Some 'men' were left stationed in the garden to guard particular paths and points of access to the winter barracks, and some were hidden inside decorative pots in the living room and behind plates in the kitchen to act as sentries and guards. 


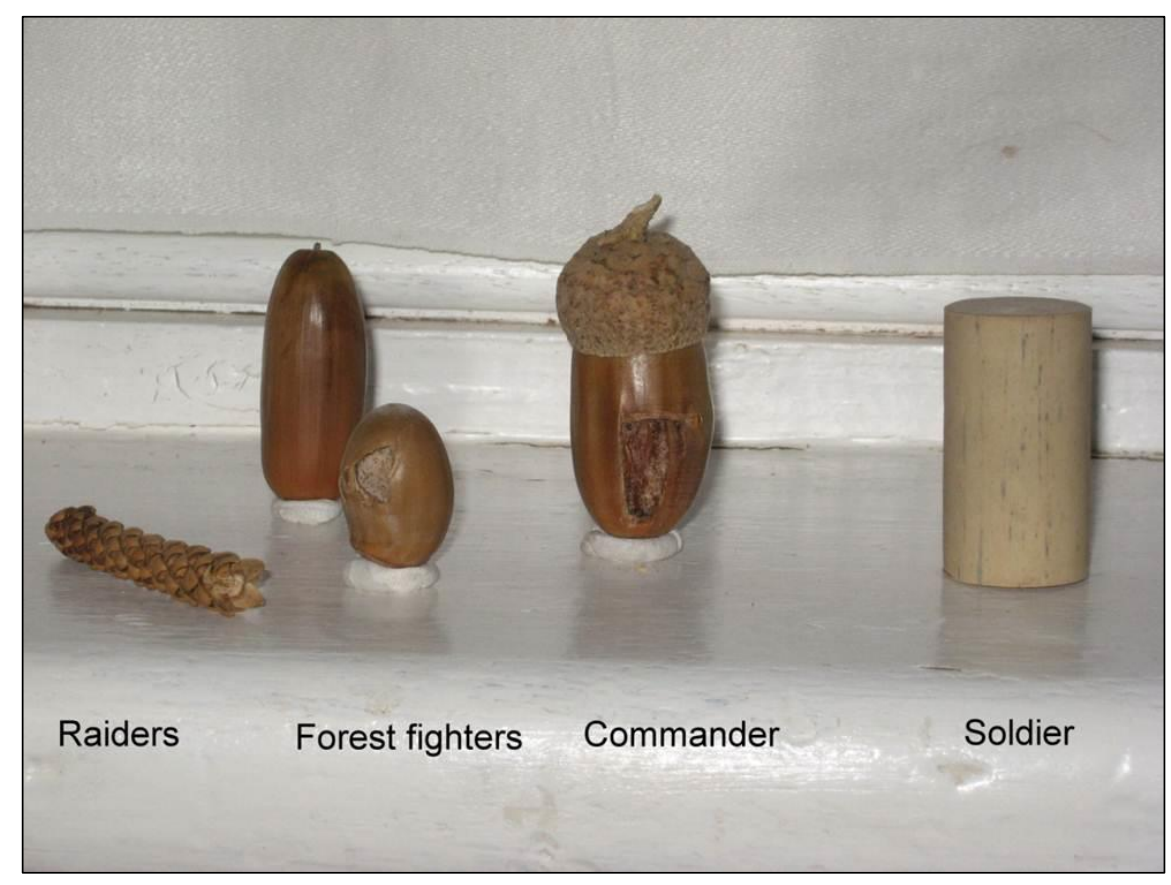

Figure 14: Resemiotised objects

In this example of multimodal play, Mikki used things that his parents had discarded to assemble a vast army. This was an outward expression of a fantasy nurtured by his fascination with history, stories of war and conquest, and images from the computer game Age of Empires and an abridged illustrated version of Tolkien's Lord of the Rings, here creatively transformed as his own invention. In this role play he was in charge, the author and agent, as he had used 'what was to hand' to design something that perfectly expressed his interest and intentions. It was a highly affective engagement, and once I had 'sanctioned' the Empire through my interest, he announced in an animated voice that this was "the most important thing in the world" to him. A few select friends were allowed to enter the winter barracks and they spent hours discussing how to improve and perfect the design. Several other boys in the neighbourhood subsequently began their own empires, and Mikki indicated to me that he might need to send 500 troops to this or that person's house to help them get started.

Mikki's 'scanning' of his environment for things that could be incorporated into his Empire is illustrative of Kress's (1997:104) reference to the child's "voracious appetite for semiotic recycling" and his "ever-searching eye, guided by a precise sense of design, both for material and for shape". As Kress (1997:33) so succinctly comments:

Children see the complexity of the meaningful cultural world with absolute clarity; and in their making of meaning they construct elaborate, complex representations of that world - out of the materials which are to hand... In this process they construct complex alternative systems of representations, never arbitrarily, never simply copying, always producing forms which reveal and bear the logic and interest of their sign-maker's cognitive actions and affective interests.

The semiotic potential of these things is never predictable, as they do not in any way match conventional expectations of what is 'useful' or 'suitable' for making meaning. In addition, 
their meanings are fluid and shifting. For example, at one point Mikki used champagne corks to represent the Empire's commanders; later, he supplemented these with large capped acorns with marks cut into them. Mikki explained this as the effect of availability: when he ran out of champagne corks, he had to create a new signifier drawing on 'what was to hand', and acorns with caps were more plentiful; their size and shape also sufficiently matched the design criteria for signifying 'commander'. In a similar vein, the location and layout of the Empire was constantly changing as the boys reworked the design to improve its fortifications and efficacy, and to expand its reach beyond the walls of our garden into neighbouring homes and beyond. The infinite possibilities of fluid, unbounded meanings shifting across modes and spaces allowed Mikki and his friends to endlessly rework their imaginary landscapes according to their interest. Here Mikki's play forms an ongoing series of transmodal moments - with a strong focus on the materiality of the sign and its temporal and spatial dimensions (Newfield 2009) shaped by and speaking back to his own socio-cultural context. Thus this act of sign-making and re-making, involving numerous motivated choices and actions, allows Mikki to exercise his agency and assert his voice; even as his sign-making is constrained by his socio-cultural context and the resources that are to hand.

\section{Conclusion}

The sign-maker's interest, argues Kress (2000:156), is always both personal and social, and shaped by their cognitive and affective processes. In a social semiotic, multimodal approach to learning, creativity is valued and sign-making is recognised as a complex process of design in which individuals are seen not as users of a stable system, but as remakers and transformers of "sets of representational resources ... in a situation where a multiplicity of representational modes are brought into textual compositions" (Kress 2000:160). This approach allows for a deeper understanding of the relations between creativity and learning and is premised on the notion that allowing children to create 'variations on a theme' and rework meanings across modes is key to cognitive and affective development. In particular, Kress argues, non-verbal modes of expression engage children's sense of design, both in terms of arrangement and in terms of innovation, both of which are essential for the development of literacy (e.g. page layout) and successful participation in our information-based economies and highly technologised communicative landscapes.

Although this case study focuses on home literacies, it offers some suggestions for the development of school-based literacies. As the above case study has shown, my two children prefer very different modes of expression, yet the school curriculum generally privileges writing as the primary and preferred semiotic system. Other multimodal forms of expression are generally 'demoted' within the school curriculum or restricted to particular domains or timetable slots (e.g. handwork, music, drama), thereby further devaluing them as potential semiotic forms and limiting the possibilities for the free-ranging across modes that Kress advocates. Writing, drawing and role play are structured as separate activities, and children are often given the instruction to 'write first, then illustrate'. Drawing from this case study, 'draw first, then write' might be a better way to start.

The inclusion of a wider range of semiotic modes and literacy tasks in the classroom could also be a way to engage a wider range of children. As Kress (1997:109) argues, different children have different dispositions and preferences for self-expression. Allowing the child to choose the mode that best suits their disposition would help engage their affect, thereby increasing their 
motivation to learn. It may be a way of developing their self-confidence in themselves as cultural agents; as people with voice. As Kress (1997:79) has argued, "the paths into writing are many, enormously complex, and long. It is the adult's simplistic view which obscures this".

\section{Acknowledgements}

My sincere thanks to Cathy Kell for very helpful comments on an earlier draft of this paper. And thanks, of course, to Mikki and Andrea for enriching our lives in so many ways.

\section{References}

Archer, A and D. Newfield. 2013. Challenges and opportunities of multimodal approaches to education in South Africa. In A. Archer and D. Newfield (eds.) Multimodal approaches to research and pedagogy: Recognition, resources and access. New York: Routledge. pp. 1-18.

Blommaert, J. 2005. Discourse: A critical introduction. Cambridge: Cambridge University Press.

Cope, B. and M. Kalantzis. 2000. Multiliteracies: Literacy learning and the design of social futures. London: Routledge.

Cox, M. 1993. Children's drawings of the human figure. Hove: Lawrence Erlbaum.

Cox, M. 2005. The pictorial world of the child. Cambridge: Cambridge University Press.

Crafton, L., P. Silvers and M. Brennan. 2009. Creating a critical multiliteracies curriculum: Repositioning art in the early childhood classroom. In M. J. Narey (ed.) Making meaning: Constructing multimodal perspectives of language, literacy and learning through arts-based early childhood education. New York: Springer. pp. 31-51.

Early, M. and M. Kendrick. 2015. Literacy in transcultural, cosmopolitan times: A call for change (LTCT2015). Discussion paper: $21^{\text {st }}$ Century Literacies: Multiliteracies Reconsidered. Available online: http://werklund.ucalgary.ca/ltct/files/ltct/early-kendrick.pdf (Accessed 27 November 2015).

Hofstadter, D. 1985. Metamagical themas: Questing for the essence of mind and pattern. London and New York: Penguin Books.

Jewitt, C. (ed.) 2009. The Routledge handbook of multimodal analysis. London: Routledge.

Jewitt, C. and G. Kress. (eds.) 2003. Multimodal literacy. New York: Peter Lang.

Kress, G. 1997. Before writing: Rethinking the paths to literacy. London: Routledge.

Kress, G. 2000. Design and transformation. In B. Cope and M. Kalantzis (eds.) Multiliteracies: Literacy learning and the design of social futures. Routledge: London. pp. 153-161. 
Kress, G. 2001. From Saussure to critical sociolinguistics: The turn towards a social view of language. In M. Wetherell, S. Taylor and S. Yates (eds.) Discourse theory and practice: A reader. London: Thousand Oaks. pp. 29-38.

Kress, G. 2010. Multimodality: A social semiotic approach to contemporary communication. London: Routledge.

Kress, G. and C. Jewitt. 2003. Introduction. In C. Jewitt and G. Kress (eds.) Multimodal literacy. New York: Peter Lang. pp. 1-18.

Kress, G. and T. Van Leeuwen. 1996. Reading images: The grammar of visual design. Oxon: Routledge.

Labov, W. 1972. Language in the inner city. Philadelphia, University of Pennsylvania Press. pp. 354-396.

Lillis, T. 2013. The sociolinguistics of writing. Edinburgh: Edinburgh University Press.

Luquet, G. 1913. Les dessins d'un enfant. Paris: Alcan.

Luquet, G. 1927. Le dessin enfantin. Paris: Alcan.

Newfield, D. 2009. Transmodal semiosis in classrooms: Case studies from South Africa. Doctoral dissertation. London: University of London Institute of Education. Available online: http://ethos.bl.uk/OrderDetails.do?uin=uk.bl.ethos.534882. (Accessed 25 November 2015).

Newfield, D. 2013. Transformation, transduction and the transmodal moment. In C. Jewitt (ed.) The Routledge handbook of multimodal analysis ( $2^{\text {nd }}$ edition). London: Routledge. pp. 100-115.

Paget, G. 1932. Some drawings of men and women made by children of certain non-European races. Journal of the Royal Anthropological Institute 62:127-144.

Pahl, K. 2003. Children's text-making at home: Transforming meaning across modes. In C. Jewitt and G. Kress (eds.) Multimodal literacy. New York: Peter Lang. pp. 139-154.

Piaget, J. 1954. The construction of reality in the child. New York: Basic Books.

Stein, P. and L. Slonimsky. 2006. An eye on the text and an eye on the future: Multimodal literacy in three Johannesburg families. In K. Pahl and J. Rowsell (eds.) Travel notes from the New Literacy Studies. Bristol: Multilingual Matters. pp. 118-146.

Saussure, F. de. 1916/1959. Course in general linguistics. C. Bally, A. Sechehaye and A. Riedlinger (eds). Trans. W. Baskin. New York: Philosophical Library.

Stein, P. 2003. The Olifantsvlei Fresh Stories Project: Multimodality, creativity and fixing in the semiotic chain. In C. Jewitt and G. Kress (eds.) Multimodal literacy. New York: Peter Lang. pp. 123-138. 
Stein, P. 2007. Multimodal pedagogies in diverse classrooms: Representation, rights and resources. London: Routledge.

Street, B. 1995. Social literacies: Critical approaches to literacy in development, ethnography and education. London: Longman.

Street, B., K. Pahl and J. Rowsell. 2009. Multimodality and New Literacy Studies. In C. Jewitt (ed.) The Routledge handbook of multimodal analysis. London: Routledge. pp. 191-200. 